\title{
Arginine metabolic control of airway inflammation
}

\author{
Kewal Asosingh,' Chris D. Lauruschkat, ${ }^{1}$ Mario Alemagno, ${ }^{1}$ Matthew Frimel, ${ }^{1}$ Nicholas Wanner, ${ }^{1}$ \\ Kelly Weiss, ${ }^{1}$ Sean Kessler, ${ }^{1}$ Deborah A. Meyers, ${ }^{2}$ Carole Bennett, ${ }^{1}$ Weiling Xu, ${ }^{1}$ and Serpil Erzurum ${ }^{1,3}$ \\ 'Department of Inflammation and Immunity, Lerner Research Institute, Cleveland Clinic, Cleveland, Ohio, USA. ${ }^{2}$ Division of \\ Genetics, Genomics and Precision Medicine, Department of Medicine, College of Medicine, University of Arizona, Tucson, \\ Arizona, USA. ${ }^{3}$ Respiratory Institute, Cleveland Clinic, Cleveland, Ohio, USA
}

Inducible nitric oxide synthase (iNOS) and arginase-2 (ARG2) share a common substrate, arginine. Higher expression of iNOS and exhaled NO are linked to airway inflammation in patients. iNOS deletion in animal models suggests that eosinophilic inflammation is regulated by arginine metabolism. Moreover, ARG2 is a regulator of Th2 response, as shown by the development of severe eosinophilic inflammation in $A R G 2^{-/-}$mice. However, potential synergistic roles of iNOS and ARG2 in asthma have not been explored. Here, we hypothesized that arginine metabolic fate via iNOS and ARG2 may govern airway inflammation. In an asthma cohort, ARG2 variant genotypes were associated with arginase activity. ARG2 variants with lower arginase activity, combined with levels of exhaled NO, identified a severe asthma phenotype. Airway inflammation was present in WT, ARG2 $2^{-/-}$, iNOS ${ }^{-/-}$, and $A R 2^{-/-} / \mathrm{iNOS}^{-/-}$mice but was greatest in $\mathrm{ARG2}^{-/-}$. Eosinophilic and neutrophilic infiltration in the $A R \mathrm{C2}^{-/-}$mice was abrogated in $A R \mathrm{C2}^{-/-} / \mathrm{iNOS}^{-/-}$animals. Similarly, angiogenic airway remodeling was greatest in $A R C 2^{-/-}$mice. Cytokines driving inflammation and remodeling were highest in lungs of asthmatic $A R C 2^{-1-}$ mice and lowest in the NNOS $^{-1-}$. ARG2 metabolism of arginine suppresses inflammation, while iNOS metabolism promotes airway inflammation, supporting a central role for arginine metabolic control of inflammation.

Conflict of interest: The authors have declared that no conflict of interest exists.

Copyright: (ㄷ) 2020, American Society for Clinical Investigation.

Submitted: January 29, 2019 Accepted: December 18, 2019 Published: January 30, 2020.

Reference information: JCI Insight. 2020;5(2):e127801.

https://doi.org/10.1172/jci. insight.127801.

\section{Introduction}

Genetic and environmental factors are important to the genesis and progression of asthma (1). Over the past few years, accumulating evidence suggests that changes in metabolism regulates inflammation and $\mathrm{T}$ cell function (2). Current concepts suggest that arginine metabolism affects immune cell function via both mitochondrial and nonmitochondrial mechanisms of action $(3,4)$. Recently, our group identified that arginine metabolism is a key driver of Th2 airway inflammation (4). Arginine is a semiessential amino acid metabolized by several enzymes, including the inducible nitric oxide synthase (iNOS) in the cytosol and by arginase-2 (ARG2) in the mitochondria (5). Arg1, another enzyme in arginine metabolism, is primarily expressed in the cytosol of hepatic cells as part of the urea cycle $(6,7)$. There are abundant data linking both iNOS and ARG2 enzymatic pathways to asthma pathophysiology. ARG2 gene variants were some of the earliest and continue to be the most consistent single nucleotide polymorphisms (SNPs), discovered in genome-wide association studies (GWAS) of asthma, strongly linked to asthma origins and severity (ARG2 rs7140310 [T/G], rs742869 [G/A], rs3742879 [A/G]) (8-10) The relationship between ARG2 SNPs and the expression or activity of arginase is currently unknown. $A R G 2$ lies within an asthma linkage region on chromosome 14q24 (11). Arginine metabolism via iNOS and ARG2 is higher in asthmatics than in healthy individuals $(12,13)$. Loss of arginine metabolism in $A R G 2^{-1-}$ mice is also associated with more severe airway inflammation in the OVA mouse Th2 model of allergic respiratory inflammation.

High fractional exhaled $\mathrm{NO}\left(\mathrm{F}_{\mathrm{E}} \mathrm{NO}\right)$ in human asthma is generated by iNOS expressed in the airway epithelium (14-26), where it catalyzes the conversion of arginine to NO and citrulline (14-26). Despite greater iNOS and $\mathrm{F}_{\mathrm{E}} \mathrm{NO}$, arginine levels in asthma epithelium are 3-fold higher than normal, and citrulline levels are very low (21). This, together with the inconsistent effects of NOS inhibitors in asthma (23) and linkage of $A R G 2$ to asthma, suggests that an NO-centric view of arginine metabolic effects in asthma is incomplete (23). Here, we investigate the concept that arginine regulates pathways of inflammation important in asthma 
origins and severity. To test this idea, asthmatics with genetic variants of ARG2 were evaluated for severity of asthma in the context of high and low levels of $\mathrm{F}_{\mathrm{E}} \mathrm{NO}$. In mechanistic studies, WT, $\mathrm{NOS}^{\nu^{--}}, A R G 2^{-{ }^{-}}$, and in-house-generated $i N O S^{-/ /} / A R G 2^{-/-}$animals were evaluated in a house dust mite extract (HDME) model of airway inflammation, which is typified by eosinophilic and neutrophilic inflammation.

\section{Results}

ARG2 variant genotypes are associated with arginase activity. Characteristics of the study participants have been previously described $(27,28)$ and are shown in Supplemental Table 1 (Supplemental material available online with this article; https://doi.org/10.1172/jci.insight.127801DS1), grouped by asthma versus control and by asthma with high and low $\mathrm{F}_{\mathrm{E}} \mathrm{NO}$. Asthmatics were older than healthy controls (age [yr]: control $30 \pm 1$; asthma $39 \pm 1 ; P<0.0001$ ) but similar in sex (sex [M/F]: control, 59/97; asthma, 188/337; $P=0.6$ ). Among the several ARG2 SNPs linked to asthma, rs742869 is a known common variant (major/minor allele: $\mathrm{A} / \mathrm{G}$ ), allowing us to have sufficient power among heterozygotes and homozygotes for comparisons (8-10). Compared with healthy controls, asthmatics tended to have the highest frequency of A/A (homozygous for the minor A allele) (GG/GA/AA: control, 38/71/47; asthma, 87/239/199; $P=0.05$ ANOVA; GG vs. AA, $P=$ 0.01 ) (Table 1). Among asthmatics, the comparison of AA vs. GG was significant $(P=0.015)$. Adjusted OR for age, sex, and smoking history was 1.82 , with $P=0.024$. Arginase activity tended to be the lowest in asthmatics with $\mathrm{A} / \mathrm{A}$ allele (arginase activity, $\mu \mathrm{mol} / \mathrm{mL} / \mathrm{h}$ : GG, $0.63 \pm 0.13 ; \mathrm{AA}, 0.37 \pm 0.05 ; P=0.04$ ) (Table 1). There were no differences in severity, lung function, inflammation, and $\mathrm{F}_{\mathrm{E}} \mathrm{NO}$ across different alleles, but $\mathrm{BMI}$ and IgE trended to be higher in the AA genotype asthmatics (Table 1). ARG2 rs742869 genotypes have been related to phenotypes of obesity, airflow obstruction, hyperreactivity, and blood eosinophils and IgE levels. We further analyzed asthmatics dichotomized by high and low $\mathrm{F}_{\mathrm{E}} \mathrm{NO}$ levels (Figure 1, A-F). A subphenotype group of patients with low $\mathrm{F}_{\mathrm{E}} \mathrm{NO}$ and $A R G 2 \mathrm{G} / \mathrm{G}$ allele (with highest arginase activity) had the highest BMI $\left(P<0.001,2\right.$-tailed ANOVA, Figure 1A), the highest $\mathrm{PC}_{20}$ (provocative concentration of methacholine causing a $20 \%$ fall in $\mathrm{FEV}_{1} ; P=0.01$, 2-tailed ANOVA, Figure 1C), and the lowest blood eosinophil levels $\left(P<0.0001\right.$, 2-tailed ANOVA, Figure 1D). Asthmatics with high $\mathrm{F}_{\mathrm{E}} \mathrm{NO}$ and the $A R G 2 \mathrm{~A} / \mathrm{A}$ genotype (with low arginase activity) had the highest blood $\operatorname{IgE}$ levels $(P=0.0002$, 2-tailed ANOVA, Figure 1E). No sex differences were observed in our cohort. IgE levels, percent eosinophils, and $\mathrm{F}_{\mathrm{E}} \mathrm{NO}$ were higher in male asthmatics compared with female, while lung function was lower (male vs. female asthmatics: IgE, $249 \pm 406$ male, $177 \pm 263$ female, $P<0.001$; percent eosinophils, $4.3 \pm 2.9$ male, $3.6 \pm 3.0$ female, $P<0.001 ; \mathrm{F}_{\mathrm{E}} \mathrm{NO}$, $44.2 \pm 38$ male, $39.2 \pm 43$ female, $P<0.01$; baseline forced expiratory volume in 1 second $\left(\mathrm{FEV}_{1}\right)$ percent predicted, $67.4 \pm 22.9$ male, $76.6 \pm 21.9$ female, $P<0.001 ; \mathrm{FEV}_{1} /$ forced vital capacity (FVC), $0.64 \pm 0.12$ male, $0.72 \pm 0.12$ female, $P<0.001$ ). Overall, the findings suggest that genotypes associated with arginase activity may interact with $\mathrm{F}_{\mathrm{E}} \mathrm{NO}$ levels to manifest as different asthma phenotypes. These findings prompted us to study $A R G 2$ and $i N O S$ pathway interactions in a mouse model of airway inflammation.

iNOS ${ }^{-/} / A R G 2^{-/-}$mice are viable and fertile. $i N O S^{-/-} / A R G 2^{-/-}$animals were generated by crossbreeding

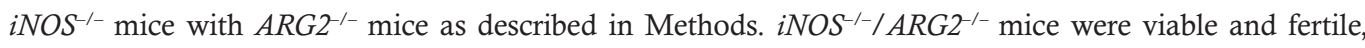

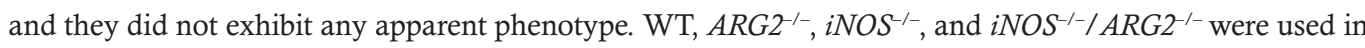
a HDME model described below. Plasma levels of arginine quantified in naive WT and $A R G 2^{--}$mice were significantly increased in $A R G 2^{-/-}$animals, consistent with the genotype (plasma arginine levels $[\mu \mathrm{m} / \mathrm{L}]$; WT, $n=8,119 \pm 7$; ARG2 $\left.{ }^{-/-}, n=9,244 \pm 27 ; P<0.002\right)$.

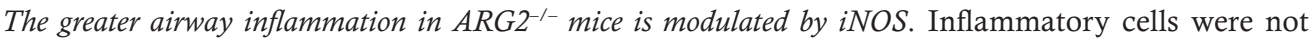
observed in naive or saline exposed WT, $A R G 2^{-1-}, i N O S^{-/}$, and $i N O S^{-/ /} A R G 2^{-1-}$ in lung tissue sections stained with H\&E (Figure 2A). All 4 genotypes developed airway inflammation upon exposure to HDME, but $A R G 2^{-/-}$mice consistently had the highest numbers of inflammatory cell influx into the lungs (Figure 2A). Quantification of bronchoalveolar lavage (BAL) cellular content showed that total cell number (Figure 2B) and number of eosinophils (Figure 2C) and neutrophils (Figure 2D) were higher in HDME-exposed $A R G 2^{-1-}$ mice than other genotypes. There were no differences in inflammatory cells between WT and $\mathrm{NNOS}^{-1-}$ animals (Figure 2, B-D). Macrophages and lymphocytes were similar across genotypes in allergen exposed groups (Figure 2, E and F). Deletion of iNOS attenuated the airway inflammation in $A R G 2^{-/-}$mice so that levels were similar to WT levels (Figure 2, A-D). These data show that deletion of the mitochondrial arginine-consuming enzyme $A R G 2$ results in exaggerated eosinophilic and neutrophilic airway inflammation, which was nullified to WT levels by the deletion of the other major arginine metabolizing enzyme iNOS. 
Table 1. Study participants with ARG2 rs742869 single nucleotide polymorphism (SNP) genotyping

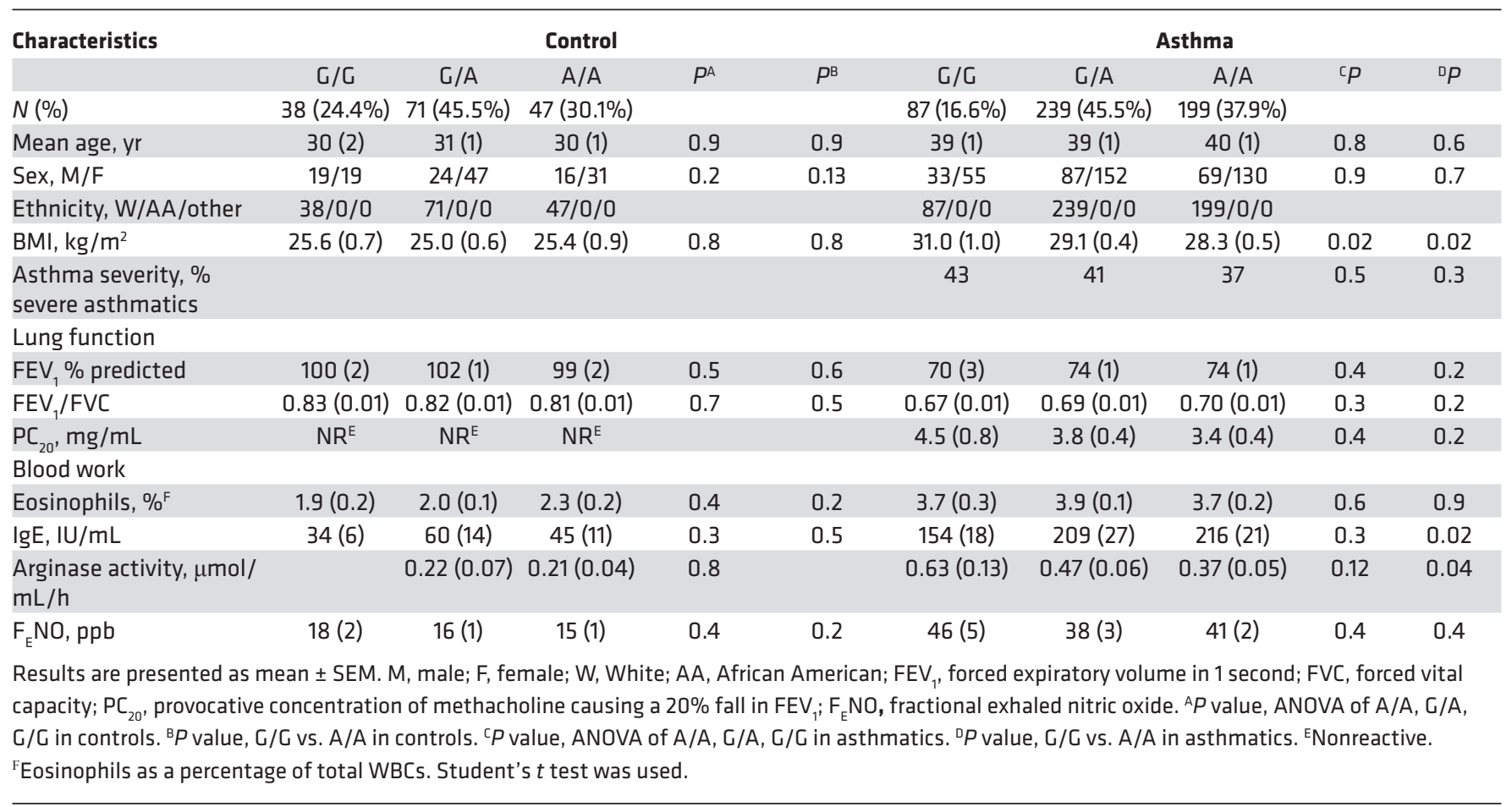

Increased angiogenic remodeling and elevated eosinophilic and neutrophilic and angiogenic cytokines in ARG2-1mice. The effect of arginine metabolism on $\mathrm{CD} 4^{+} \mathrm{T}$ cell differentiation in naive and allergen-exposed mice was analyzed using splenic T cells. IL-4-expressing CD4 ${ }^{+} \mathrm{T}$ cells (Th2) increased in all allergen-exposed genotypes compared with naive mice (Figure $3 \mathrm{~A}$ ). IL-17-expressing $\mathrm{CD} 4^{+} \mathrm{T}$ cells (Th17) were elevated in HDME-exposed WT mice, confirming that this airway inflammation model consists of mixed Th2/Th17 inflammation (Figure 3B). Th17 cells were suppressed in $A R G^{-/-}$mice, independently of allergen exposure. Naive $i N O S^{-1-}$ mice exhibited increased Th17 differentiation, as reported previously (29); however, the levels were suppressed in HDME-exposed $\mathrm{NOSS}^{-/}$. Conversely, naive $i N O S^{-/-} / A R G 2^{-1-}$ had low Th17 cells, and the percentage peaked after allergen challenge, demonstrating that an intact arginine pathway inhibits Th17 differentiation in allergen-exposed mice. IFN- $\gamma^{+} \mathrm{CD}^{+\mathrm{T}}$ cells (Th1) were high in naive $i N O S^{-/}$or $i N O S^{-/ /} / A R G 2^{-/-}$mice (Figure 3C). Allergen exposure reduced Th1 differentiation in $i N O S^{-/}$mice but not in $i N O S^{-1-} / A R G 2^{-/-}$animals, indicating that $A R G 2$ is required to decrease the Th1 response in allergen-exposed $i N O S^{-/}$mice. Deletion of $A R G 2$ increased Foxp ${ }^{+} \mathrm{CD}^{+} \mathrm{T}$ cells (Tregs), while iNOS had no effect (Figure 3D). The findings indicate that $i N O S$ and $A R G 2$ have contrasting effects on the polarization of CD4 effector T cells in naive and allergen-exposed mice. ARG2 deletion favors Tregs and inhibits Th17; however, this effect was insufficient to attenuate the exaggerated asthma phenotype.

Angiogenic remodeling is one of the most consistent characteristics of asthma airway remodeling, and it occurs in mild, moderate, and severe asthma patients (30). There is a consistent significant correlation between bronchial wall microvessel density and asthma severity in patients, which is linked mechanistically to atopic airway inflammation (30-34). Microvessel density was quantified on lung tissue sections stained for the endothelial cell marker von Willebrand Factor (vWF). Compared with saline-exposed mice, HDME increased angiogenesis in all 4 genotypes (Figure 3E). Lung microvessel density was highest in the $A R G 2^{-\prime}$ animals but was dampened in $i N O S^{-1-} / A R G 2^{-1-}$ to levels found in WT (Figure $3 \mathrm{~F}$ ). The data demonstrate that deletion of $A R G 2$ fuels angiogenic airway remodeling upon allergen exposure in the presence of an intact iNOS pathway. To understand underlying mechanisms of the increased airway inflammation and remodeling in $\mathrm{HDME}$-exposed $A R G 2^{-/-}$mice, cytokine profiles in lung tissue protein extracts or BAL, including GM-CSF, CCL20, IL-1 $\alpha$, Eotaxin-1, Eotaxin-2, IL-5, IL-1, VEGF, and IL-17, were quantified. IL-5 and eotaxin-2 are critical for eosinophilopoiesis and recruitment of eosinophils (35), while eotax- 

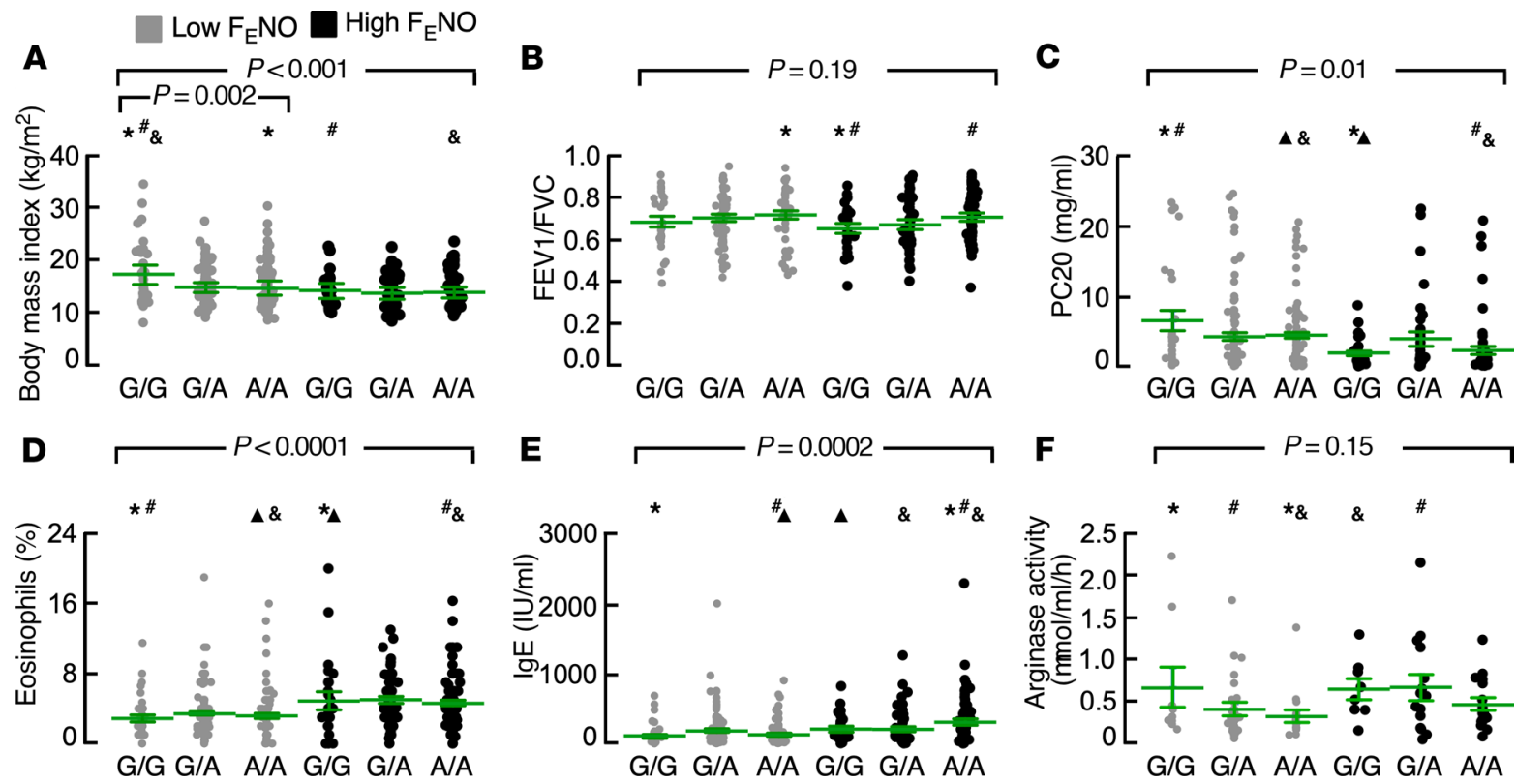

Figure 1. ARC2 rs742869 single nucleotide polymorphism (SNP) related to phenotypes of obesity, airflow obstruction, hyperreactivity, and blood eosinophils and IgE levels in asthmatics dichotomized by high and low fractional exhaled nitric oxide $\left(F_{E} N O\right)$ levels. Each dot represents data from 1 patient; gray indicates low $\mathrm{F}_{\mathrm{E}} \mathrm{NO}$, and black represents high $\mathrm{F}_{\mathrm{E}} \mathrm{NO}$. (A) BMI was significantly different among genotypes of ARG2 rs742869 SNP in asthmatics dichotomized by high $F_{E} N O(\geq 35 \mathrm{ppb})$ and low $F_{E} N O(<35 \mathrm{ppb})$. ${ }^{*} P=0.0008$ low $F_{E} N O$ and $G / G$ vs. low $F_{E} N O$ and $A / A$, ${ }^{*} P=0.002$ low $F_{E} N O$ and $G / G$ vs. high $F_{E} N O$ and $G / G$, and ${ }^{~} P<0.0001$ low $F_{E} N O$ and $G / G$ vs. high $F_{E} N O$ and $A / A$. (B) Ratio of forced expiratory volume in 1 second $\left(F E V_{1}\right) /$ forced vital capacity $(F V C)$ tended to be different among genotypes in asthmatics dichotomized by $F_{E} N O$. ${ }^{*} P=0.03$ low $F_{E} N O$ and $A / A$ vs. high $F_{E} N O$ and $G / G$, and ${ }^{\#} P$ $=0.03$ high $F_{E} N O$ and $G / G$ vs. high $F_{E} N O$ and $A / A$. (C) $P C_{20}$ was significantly different. ${ }^{*} P=0.002$ low $F_{E} N O$ and $G / G$ vs. high $F_{E} N O$ and $G / G$, ${ }^{*} P=0.0007$ low $F_{E} N O$ and $G / G$ vs. high $F_{E} N O$ and $A / A,{ }^{\Delta} P=0.04$ low $F_{E} N O$ and $A / A$ vs. high $F_{E} N O$ and $G / G$, and ${ }^{E} P=0.01$ low $F_{E} N O$ and $A / A$ vs. high $F_{E} N O$ and $A / A$. (D) Blood eosinophil levels were significantly different. ${ }^{*} P=0.01$ low $F_{E} N O$ and $G / G$ vs. high $F_{E} N O$ and $G / G, \# P=0.005$ low $F_{E} N O$ and $G / G$ vs. high $F_{E} N O$ and $A / A, \Delta P$ $=0.01$ low $F_{E} N O$ and $A / A$ vs. high $F_{E} N O$ and $G / G$, and ${ }^{8} P=0.003$ low $F_{E} N O$ and $A / A$ vs. high $F_{E} N O$ and $A / A$. (E) Blood lgE levels were significantly different. ${ }^{*} P=0.0001$ low $F_{E} N O$ and $G / G$ vs. high $F_{E} N O$ and $A / A,{ }^{*} P<0.0001$ low $F_{E} N O$ and $A / A$ vs. high $F_{E} N O$ and $A / A, \triangle P=0.02$ low $F_{E} N O$ and $A / A$ vs. high $F_{E} N O$ and $G / G$, and ${ }^{E} P=0.02$ high $F_{E} N O$ and $G / A$ vs. high $F_{E} N O$ and $A / A$. (F) Serum arginase activity tended to be different among genotypes in asthmatics dichotomized by $F_{E} N O{ }^{*} P=0.04$ low $F_{E} N O$ and $G / G$ vs. low $F_{E} N O$ and $A / A$, ${ }^{*} P=0.03$ low $F_{E} N O$ and $G / A$ vs. high $F_{E} N O$ and $G / A$, and ${ }^{\varepsilon} P=0.04$ low $F_{E} N O$ and $A / A$ vs. high $F_{E} N O$ and $G / G$. Student's $t$ test was used for group comparisons and 1-way ANOVA was used for comparisons of more than 2 groups.

in-2 also exerts angiogenic activity via CCR3 on bronchial endothelial cells (36). IL-17 mediates neutrophilic airway inflammation and induces angiogenesis (37). IL-5, eotaxin-2, and IL-17 were differentially expressed among WT, $A R G 2^{-/-}, \mathrm{NOS}^{-/-}$, and $i \mathrm{NOS}^{-/-} / \mathrm{ARG}^{-{ }^{--}}$mice exposed to HDME (Figure 3, G-I). IL-5 was significantly lower in $i N O S^{-/-}$and $i N O S^{-/-} / A R G 2^{-/-}$mice compared with $A R G 2^{-/}$, and a similar trend was observed in WT animals $\left(P<0.073 \mathrm{WT}\right.$ vs. ARG2 $\left.2^{--}\right) . A R G 2^{--}$animals had the highest levels of eotaxin-2 and IL-17, which returned to WT levels in $i N O S^{-1-} / A R G 2^{-/-}$. Levels were comparable between WT and $\mathrm{iNOS}^{-/-}$mice. Other neutrophil-specific chemokines KC, MIP-2, and LIX were significantly elevated in the HDME group compared with saline-exposed mice (Figure 3, J-L). Levels were similar across the different genotypes within each group. No differences were observed in airway hyperreactivity and mucus cell metaplasia (data not shown). The results suggest that mitochondrial ARG2-mediated arginine metabolism regulates expression of pulmonary eosinophilic/neutrophilic and angiogenic cytokines.

\section{Discussion}

This study shows that arginine metabolism is a critical modulator of severity of inflammation and remodeling in eosinophilic and neutrophilic asthma. Early GWAS showed a strong association of asthma and $A R G 1$ and $A R G 2$ gene variants $(8,10,38,39)$. Increased serum arginase activity was also quantitatively related to airflow limitation, as measured by $\mathrm{FEV}_{1}(40)$. Here, we show that arginase activity depends on specific $A R G 2$ SNPs. Common ARG2 variants that were associated with lower arginase activity, combined with high levels of $\mathrm{F}_{\mathrm{E}} \mathrm{NO}$, identified a more severe asthma phenotype. We modeled this severe asthma phenotype in the HDME $A R G 2^{-/-}$mouse models to investigate the underlying arginine metabolic pathways. $A R G 2^{-/-}, \mathrm{NNOS}^{-/-}$, and crossbreeds of these KOs were used to decipher the roles of iNOS and mitochondrial ARG2-dependent arginine metabolism. 
A
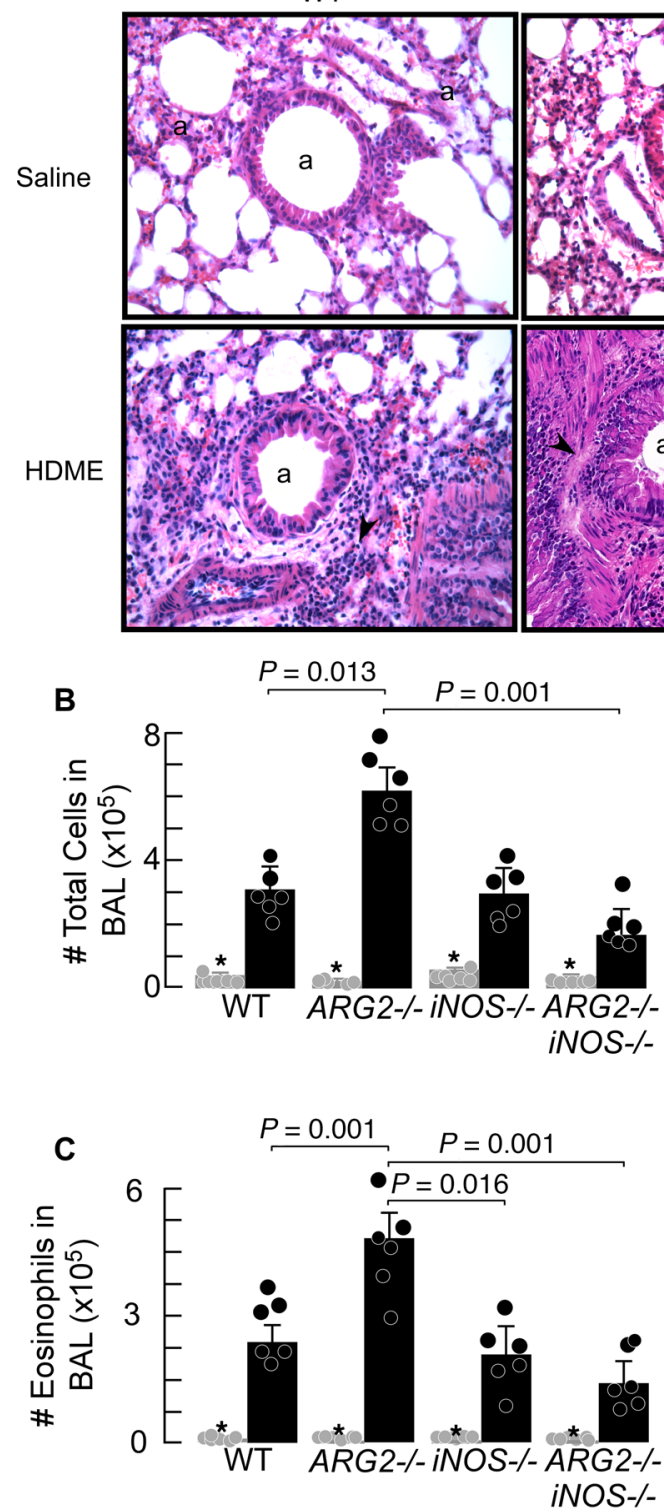

E

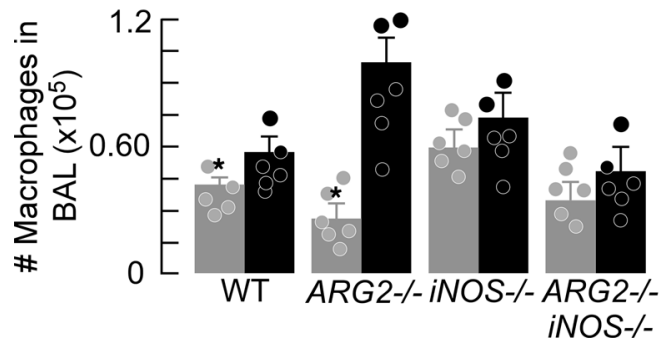

ARG2-/-
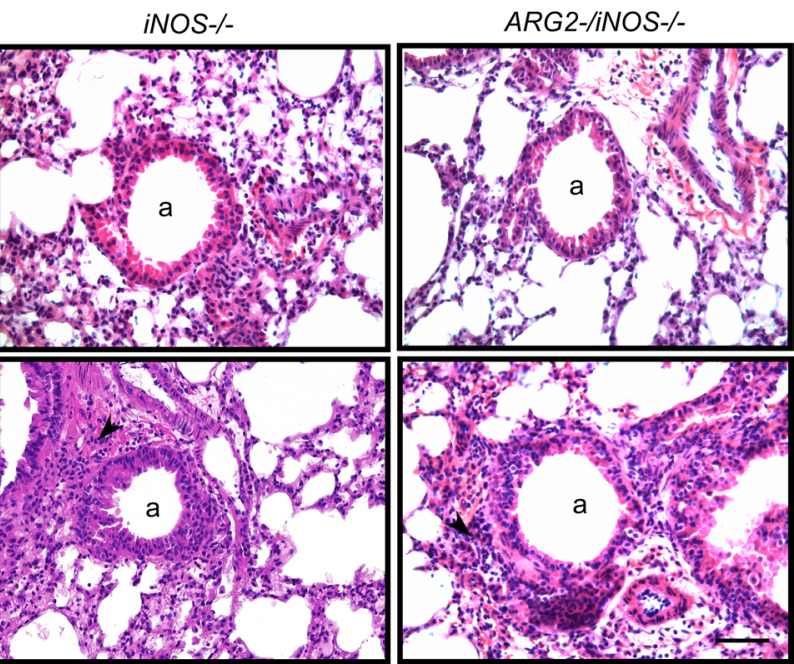

HDME

Saline
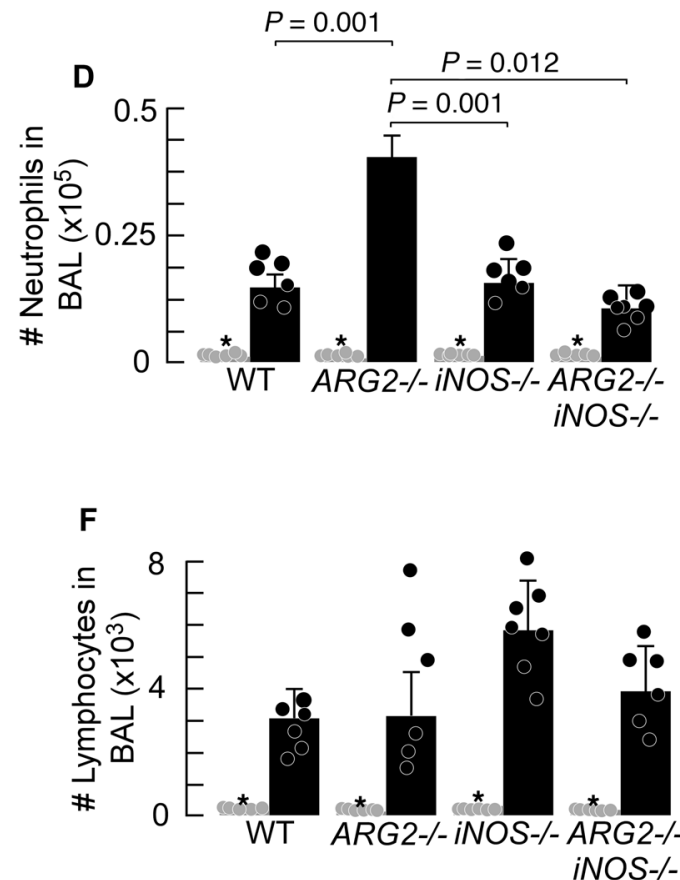

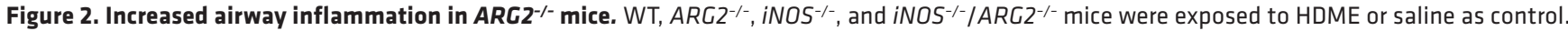
(A) Lung tissue sections stained for H\&E demonstrated that all 4 genotypes exposed to HDME developed airway inflammation, but the influx of inflammatory cells was the highest in $A R C 2^{-/-}$mice. Black arrow heads indicate foci of inflammatory cells around the airways; a, airway. Representative tissue sections are shown. Scale bar: $100 \mu \mathrm{m}$. (B-D) Differential hematopoietic cell counts in BAL showing increased total cell count (B), eosinophils (C), and neutrophils (D) in HDME exposed ARG2 $2^{-/-}$mice were inhibited in the $i N O S^{-/-} / A R G 2^{-/-}$mice. (E and F) Macrophages (E) and lymphocytes (F) were not different across HDME exposed groups. ${ }^{*} P<0.05$ between HDME and saline groups. Student's $t$ test was used for group comparisons. Each dot represents data from 1 mouse and mean \pm SEM values are shown. 
A

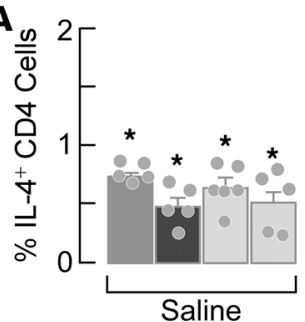

C

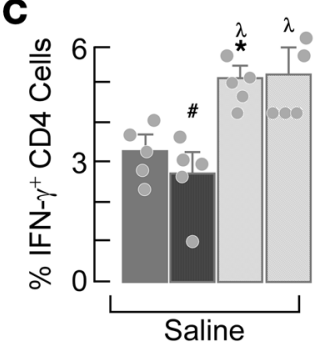

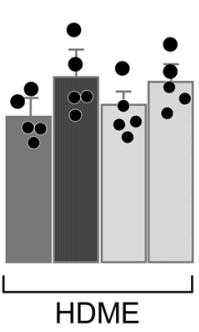

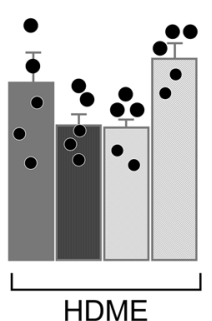

B

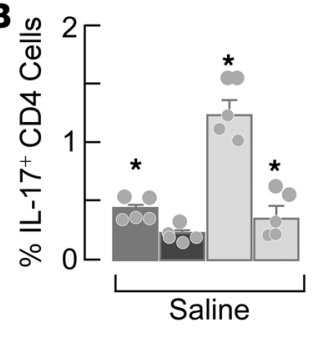

D

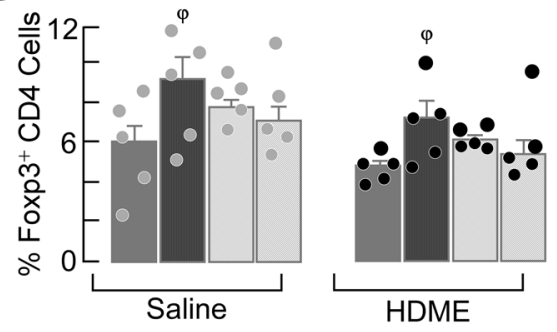

E WT ARG2-/ iNOS-/-

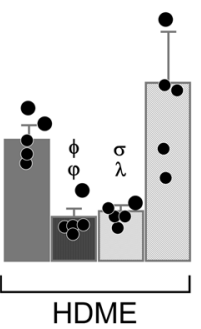

WT

ARG2\%-

iNOS-/-

ARG2-/ iNOS-/-
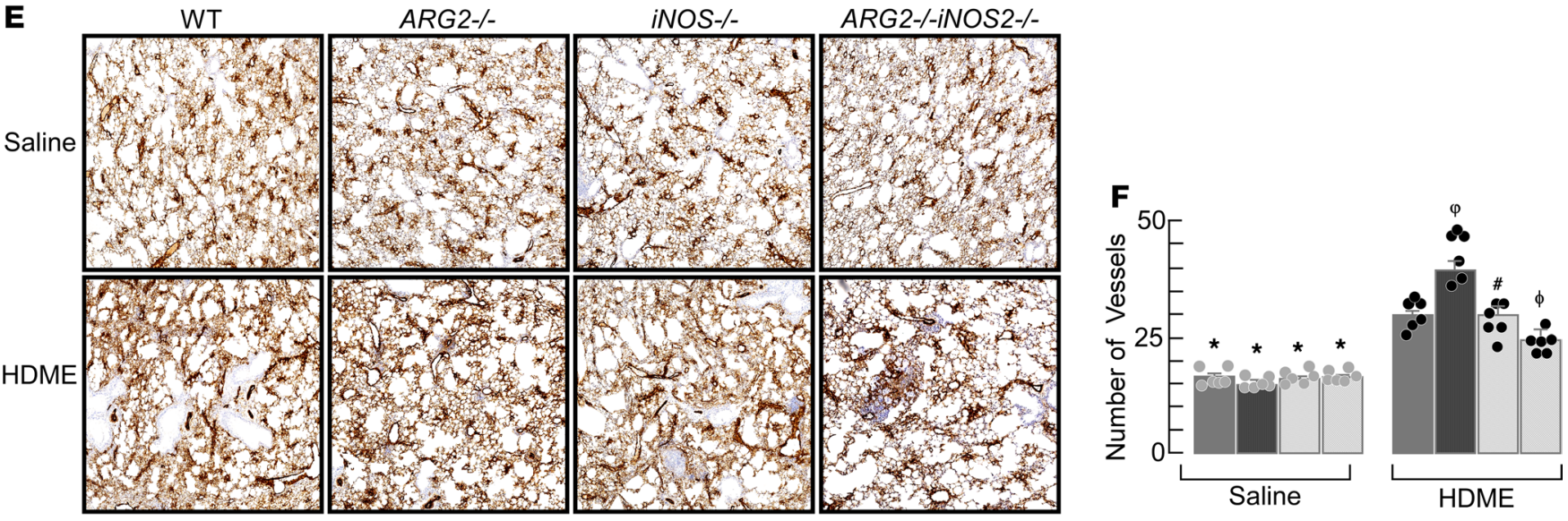
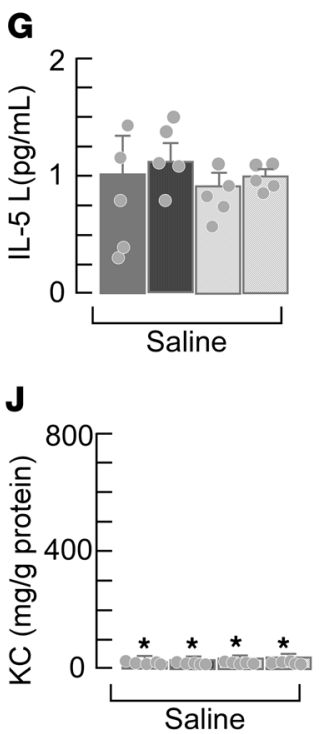
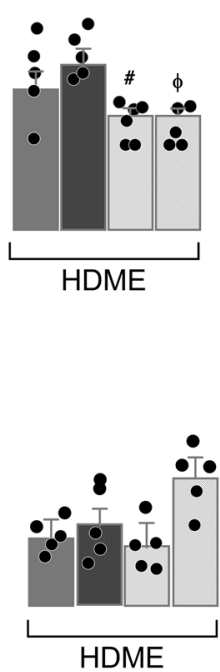

H

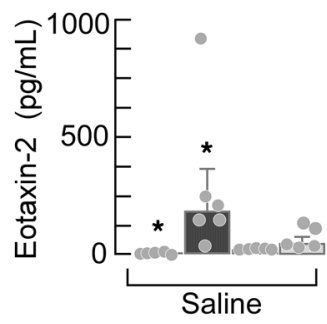

K

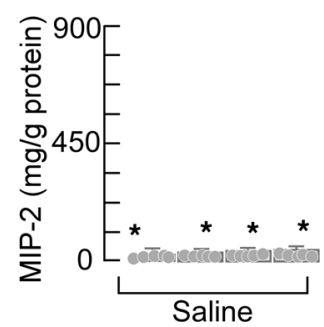

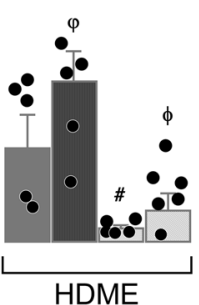

I
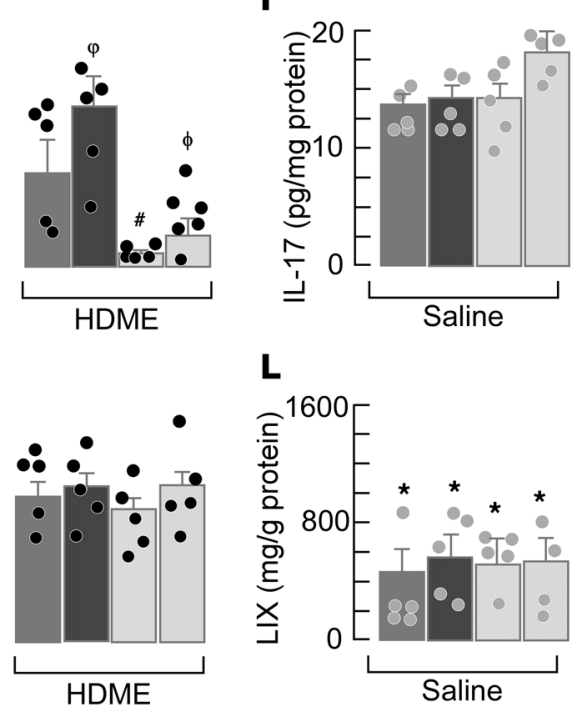

L

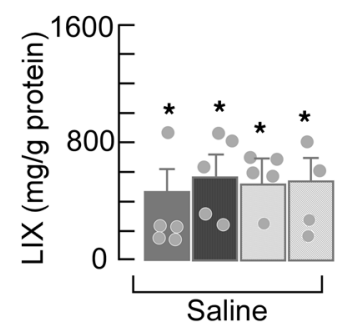

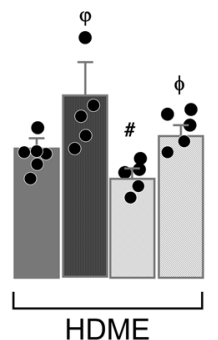

HDME

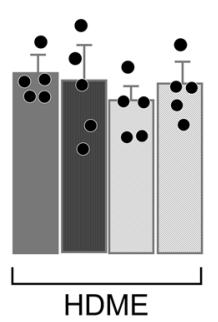

Figure 3. Increased angiogenic airway remodeling, inflammatory, and angiogenic cytokines in ARC2 $2^{-1-}$ mice. (A-D) CD4 $4^{+}$T cell polarization in $A R G 2^{-1-}$ mice analyzed using splenic T cells. Splenocytes were isolated and analyzed for effector T cell polarization. (E) vWF staining for blood vessels in paraffin-embedded lung tissue sections. Representative low- and high-power lung images from WT mice exposed to saline or HDME as shown. Original magnification $\times 200$. (F) Quantification of the microvessel density in WT, $A R G 2^{-1-}, i \mathrm{NOS}^{-1-}$, and $i \mathrm{NOS}^{-1-} / A R G 2^{-1-}$ mice exposed to HDME. The number of vessels per $2500 \mu \mathrm{m}^{2}$ area is shown. (G) IL-5 levels in BALF. (H) Eotaxin-2 levels in BALF. (I-L) IL-17, KC, MIP-2, and LIX levels in lung tissue protein extract. ${ }^{*} P<0.05$ between respective genotypes in HDME vs. saline groups. ${ }^{\phi} P<0.05$ between WT and $A R G 2^{-1-} .{ }^{\varphi} P<0.05$ between $A R G 2^{-1-}$ and $A R G 2^{-1-i N O S^{-1-}}{ }^{\circ} P<0.05$ between $i N O 5^{-1-}$ and $A R G 2^{-1-i N-}$

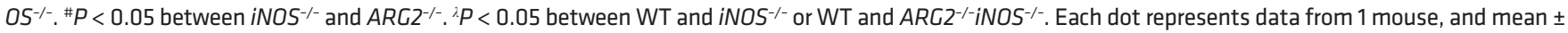
SEM values are shown. Wilcoxon test was used in $\mathbf{A}-\mathbf{D}$, and Student's $t$ test was used in $\mathbf{F}$ - $\mathbf{L}$ for group comparisons. 
All NOS isoforms are present in the airways: neuronal NOS (nNOS; NOS1) in nerves, iNOS (NOS2) in airway epithelium, and endothelial nitric oxide synthase (NOS3) in lung endothelium and in very small amounts in the airway epithelium. Genetic deletion of each of the 3 genes in mice provides information of their individual contributions. iNOS is the only NOS that is induced in the OVA allergen airway inflammation model and is associated with increased expired NO. More than $90 \%$ of $\mathrm{F}_{\mathrm{E}} \mathrm{NO}$ is attributable to iNOS using the NOS-deleted mice (41), and this parallels findings in patients in which iNOS induction occurs in allergen challenge of human asthmatics that also leads to increased $\mathrm{F}_{\mathrm{E}} \mathrm{NO}$ (42). iNOS-deleted mice have less eosinophilic inflammation than WT in the OVA model, yet continue to have airway hyperresponsiveness (43). Conversely, nNOS-deleted mice have less airway hyperreactivity but no decrement in airway inflammation. In humans, airway inflammation of many asthmatics is typified by high $\mathrm{F}_{\mathrm{E}} \mathrm{NO}$, which decreases with corticosteroids $(14,15)$. Respiratory exposure of WT mice to HDME induces a combined eosinophilic and neutrophilic airway inflammation, along with angiogenic remodeling of the lungs. Recently, we have shown that mice lacking ARG2 have worsened Th2-driven eosinophilic airway inflammation compared with WT mice in an OVA mouse model (4). The OVA model, unlike HDME, is eosinophil dominated with little to no neutrophilic inflammation. iNOS ${ }^{-/}$ mice in the OVA model had lower eosinophilic inflammation compared with WT animals (41). In contrast, our data show that $\mathrm{iNOS}^{-/-}$and WT mice in the HDME model had similar levels of airway inflammation, suggesting that iNOS metabolism of arginine has lesser effects on inflammation generated via IL-17 pathways. $A R G 2$ deficiency increased both eosinophilic and neutrophilic airway inflammation and angiogenic remodeling. While the deletion of $i N O S$ alone had no major effect on the asthma phenotype, double deletion of $i N O S$ and $A R G 2$ attenuated eosinophilic/neutrophilic airway inflammation and angiogenic remodeling. The findings reveal that (a) arginine metabolism regulates eosinophilic and neutrophilic airway inflammation and remodeling, and (b) ARG2 is a critical checkpoint in modulating inflammation and angiogenesis.

ARG2 and iNOS have a common substrate arginine, but the interactions between these 2 enzymes are more complex than substrate competition (4). We previously showed that iNOS and ARG2 interactions are not controlled by the competition for arginine but through interaction of arginine metabolism and the TCA cycle (4).

Prior studies of asthmatic patients suggested that mitochondria were more oxidative (12). ARG2 gives rise to ornithine from arginine, which can be converted to glutamate that is transformed to $\alpha$-ketoglutarate $(\alpha \mathrm{KG})$ to enter the TCA cycle. Arg2 is increased in asthmatics (4). Increased TCA cycle activity in asthma increases ATP production and levels of TCA cycle intermediates to other pathways (4). For example, $\alpha$ KG transported outside of the mitochondria serves as substrate for prolyl hydroxylase domain enzymes and inhibits hypoxia-inducible factor (HIF), an upstream regulator of Th2 cytokines (4). ARG2 deletion has previously been linked to higher HIF levels and increased Th2-driven eosinophilic inflammation and Th2 cytokine levels of IL-13 and eotaxin-1, along with increasing activation of pSTAT6 (4). Eotaxin-2, IL-5, and angiogenic remodeling of the airways in the HDME model are regulated by HIF (44). Human asthma involves Th2 (eosinophilic) with IL-17 (neutrophilic) inflammation, and IL-17 inflammation is increasingly recognized as an endotype of severe asthma (45). Eotaxin-2, mainly expressed by alveolar macrophages and proangiogenic hematopoietic progenitors, is a key driver in airway eosinophila in mouse models of airway inflammation $(7,36)$. The induction of eotaxin-2, but not eotaxin-1, by arginine metabolism suggests a specific effect on these cells. Overexpression of eotaxin-2 and IL-5 in mice resulted in spontaneous severe eosinophilic asthma (35). IL-17 is a key mediator of severe neutrophilic asthma (46). Eotaxins and IL-17 are also potent angiogenic factors in asthma, cancer, and other inflammatory disorders (36, 38, 47-53). IL-17 levels were increased in $A R G 2^{-1-}$ lungs, but Th17 differentiation was lower in these mice, suggesting a non-Th17 source of IL-17. Several other immune cells, including innate lymphoid cells, B cells, neutrophils, NKT cells, and $\gamma \delta$ T cells, also produce IL-17 (54). In obesity-associated asthma, type III innate lymphoid cells (ILC3) is a significant source of IL-17 (55). A recent report demonstrated that alveolar macrophages, and not Th17 cells, are the major source of pulmonary IL-17 in the OVA mouse model and in patients with allergic asthma (56). The non-Th17 source of the increased IL-17 levels in lungs of $A R G 2^{-1-}$ mice is tipping the balance toward an unfavorable phenotype. Alternatively, splenic $\mathrm{T}$ cells may not represent pulmonary $\mathrm{T}$ cell polarization. The findings are in keeping with our previous publication, showing that WT BM transplantation reduces IL-17 levels in the BAL in an OVA model (4).

The asthma population in this study was exclusively White, which limits extrapolation of the findings to the broader asthmatic population in general. Another limitation of this study is that SNP rs742869 is associated with lower arginase activity, but whether this results from reduced protein expression and/or lower enzymatic activity is unknown. 


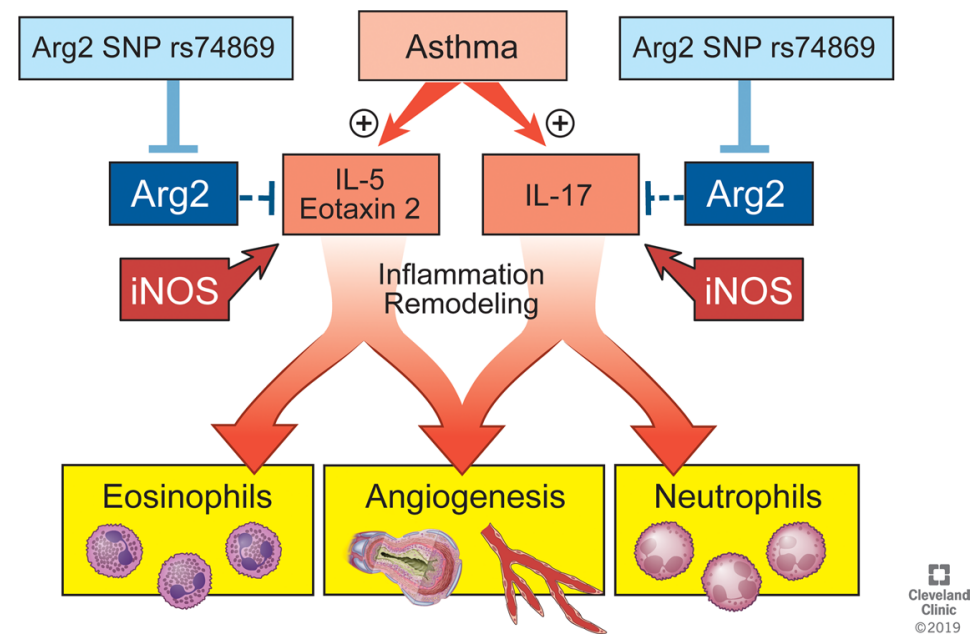

Figure 4. Arginine metabolism regulates exaggerated eosinophilic/neutrophilic asthma. Less arginase-2 activity, such as associated with by Arg2 SNP rs74869, produces an exaggerated asthmatic phenotype with higher levels of IL-5, eotaxin-2, and IL-17 resulting in severe eosinophilic/neutrophilic airway inflammation and angiogenic airway remodeling. The loss of ARG2 activity, but intact iNOS arginine metabolism, worsens the airway inflammation, suggesting that a balance among the pathways for arginine metabolism is essential in regulating inflammation. Illustration by David Schumick, BS, CMI. Reprinted with the permission of the Cleveland Clinic Center for Medical Art \& Photography @ 2019. All rights reserved.

Collectively, our findings reveal that eosinophilic and neutrophilic immune pathways that control severity of inflammation are regulated by arginine metabolism (Figure 4). Arginine metabolism via ARG2 suppresses inflammation and, via iNOS, promotes airway inflammation. New therapeutic strategies to enhance arginine metabolism by the mitochondrial ARG2 may provide benefit to patients with severe asthma.

\section{Methods}

Human participants. Adult ( $\geq 18$ years old) healthy controls and asthma patients were recruited in the Severe Asthma Research Program (SARP 1 and 2) from 2002-2011 (27, 28, 57, 58). Asthmatics were classified by cut-off point of $35 \mathrm{ppb}_{\mathrm{E}} \mathrm{NO}(16,42)$ and GWAS data on $A R G 2$ variants.

Animals and generation of $i N O S^{-/-} / A R G 2^{-/-}$mice. Female mice on a C57BL/ 6 background between the ages of 6 and 8 weeks were used in this study. WT and $i N O S^{-1-}$ mice (59) were purchased from the Jackson Laboratory. $A R G 2^{-1-}$ mice were donated by Bill O'Brain (Baylor College of Medicine, Houston, Texas, USA) (60). $i N O S^{-/-} / A R G 2^{-/-}$were generated in-house by crossbreeding $i N O S^{-/-}$and $A R G 2^{-1-}$. For genotyping, genomic DNA was isolated from mouse tissue utilizing the Bioline MyTaq Extract-PCR Kit (Bioline USA Inc.). To determine the ARG2 genotype, 35 PCR cycles were performed on $1 \mu \mathrm{L}$ of extracted DNA in a $25-\mu \mathrm{L}$ reaction volume as follows: $95^{\circ} \mathrm{C}, 30$ seconds; $55^{\circ} \mathrm{C}$, 30 seconds; $72^{\circ} \mathrm{C}, 1$ minute. A $1.1-\mathrm{kb}$ DNA fragment, indicating the presence of the ARG2 mutant allele, was generated with the primer set: ARG2 duel (5'- TCCTTTCTCCTGTCTAATTC-3') and Neo 2 (5'-GCCAACGCTATGTCCTGATA-3'). A 540-bp DNA fragment indicating the presence of the ARG2 WT allele was generated with the primer set: ARG2 WT (5'-CTAGCATCTAATTGACTGCC-3') and ARG2 duel (5'-TCCTTTCTCCTGTCTAATTC-3'). The iNOS genotype was determined in a separate PCR reaction by performing 35 cycles on $1 \mu \mathrm{L}$ of extracted DNA in a $25-\mu \mathrm{L}$ reaction volume as follows: $94^{\circ} \mathrm{C}, 30$ seconds; $59^{\circ} \mathrm{C}, 30$ seconds; $72^{\circ} \mathrm{C}, 30$ seconds. A 275 -bp DNA fragment indicating the presence of the $i N O S$ mutant allele was generated with the primer set: iNOS mutant (5'-AATATGCGAAGTGGACCTCG -3') and iNOS common (5'-ACATGCAGAATGAGTACCGG-3'). A 108-bp DNA fragment indicating the $i N O S$ WT allele was generated with the primer set: iNOS WT (5'-TCAACATCTCCTGGTGGAAC-3') and iNOS common (5'-ACATGCAGAATGAGTACCGG-3'). All DNA fragments were resolved on a 1.5\% agarose gel in TAE buffer (40 mM Tris [pH7.6], $20 \mathrm{mM}$ acetic acid, $1 \mathrm{mM}$ EDTA). All chemicals were purchased from Sigma-Aldrich. Gel images were captured with the Thermo Fisher Scientific My ECL Imager system and Adobe Photoshop CS2 Software (Adobe Systems Inc.). DNA fragment size ladders (50 bp, $100 \mathrm{bp}$, and $1 \mathrm{~kb}$ ) were also obtained from Thermo Fisher Scientific. Representative genotyping gels are shown in Figure 5A. 
A
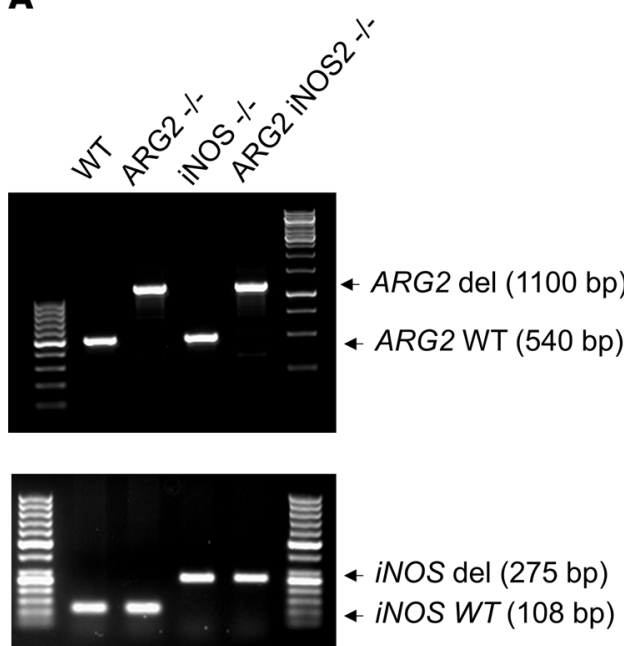

B

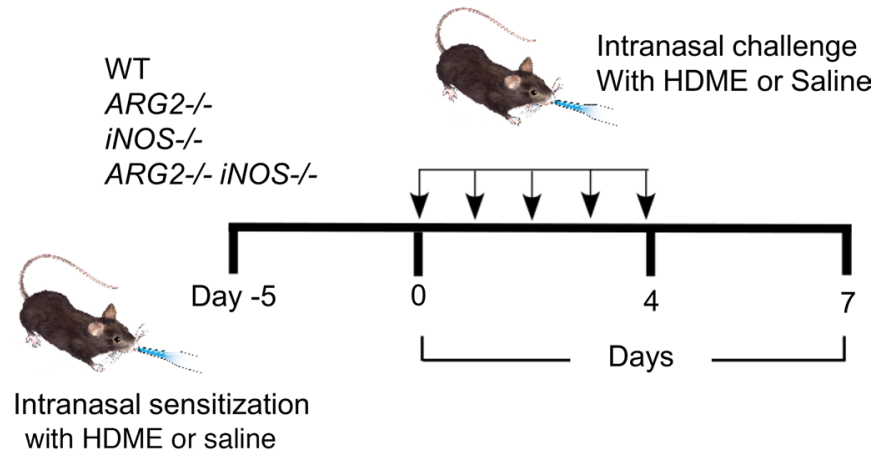

Figure 5. Mouse models. (A) Generation and genotyping of iNOS ${ }^{-1-} / A R G 2^{-/-}$mice. Interbreeding of mice carrying the iNOS mutant allele or ARG2 mutant allele was performed to generate iNOS ARG2-double mutant mice. Genotypes were confirmed by PCR on genomic DNA utilizing WT- and mutant allelespecific primers. Top gel is ARG, and lower gel is iNOS allele PCR. (B) Schematic representation of the HDME model of airway inflammation.

HDME model. A standard mouse model of HDME-induced airway inflammation was used, as illustrated in Figure 5B $(61,62)$. Isoflurane-anesthetized female mice between the ages of 8 and 11 weeks were sensitized with a single dose of $100 \mu \mathrm{g} / 50 \mu \mathrm{L} \operatorname{HDME}$ (D. pteronyssinus, RMB84M, Greer Laboratories) in saline by nasal aspiration. Five days after the allergen sensitization, animals were challenged daily for 5 successive days with $10 \mu \mathrm{g} / 50 \mu \mathrm{L}$ HDME. Analyses were performed 3 days after the final allergen challenge. Animals sensitized and challenged with saline were used as controls.

$B A L$ fluid collection and processing. Animals were euthanized by an overdose of pentobarbital (Akorn), and the lungs were lavaged with $700 \mu \mathrm{L}$ sterile saline via a cannula inserted into the trachea. The BAL fluid (BALF) was centrifuged at $300 \mathrm{~g}$ for 10 minutes. The supernatant was collected and stored at $-20^{\circ} \mathrm{C}$ for cytokine analyses, and the cell pellet was resuspended in $500 \mu \mathrm{L}$ of $2 \%$ FBS (Atlanta Biologicals) in PBS (prepared in house). BAL cell concentration was determined by counting a mixture of $10 \mu \mathrm{L}$ cell suspension, $10 \mu \mathrm{L}$ of Live/Dead and nuclear stain $(20 \mu \mathrm{g} / \mathrm{mL}$ Ethidium Bromide [Sigma-Aldrich], and $20 \mu \mathrm{g} / \mathrm{mL}$ Acridine Orange [Sigma-Aldrich] dissolved in PBS) under a fluorescent microscope (Olympus CKX41) using a hemocytometer (Hausser Scientific). Cytospins were prepared by centrifugation of 20,000 cells in $100 \mu \mathrm{L}$ of $2 \%$ FBS loaded into Shandon Cytospin 3 instrument ( $400 \mathrm{~g}$ for 4 minutes). Air-dried cytospins were stained with Kwik-Diff (Dade Behring) and mounted using Cytoseal mounting medium. A differential count of hematopoietic cells, including macrophages, neutrophils, eosinophils, and lymphocytes, was performed under a microscope. At least 200 cells were counted based on standard morphologic criteria.

Lung tissue harvest and IHC. The lung vascular bed was perfused with warm PBS via the right heart to flush out remaining blood cells. The dissected left lobe was fixed in 10\% formalin and processed for paraffin embedding and tissue sectioning. The right lung was snap frozen, stored in liquid nitrogen, and later used for cytokine quantification. Left lung tissue sections were stained with H\&E. vWF staining and microvessel quantification were performed as described previously $(36,63)$.

Cytokine quantification. Tissues of the right lobes were homogenized in PBS and subjected to repeated freeze/ thaw cycles. The suspension was centrifuged to pellet debris and supernatant - the latter was used for lung protein extract. IL-17 and GM-CSF (both from Abcam), along with CCL20, IL-1 $\alpha$, KC, MIP-2, and LIX (all from R\&D Systems), levels in BAL and lung protein extract were measured using quantitative ELISA kits. Eotaxin-1/2, IL-5, and IL-13 levels in lung and BAL were quantified using Super-X Plex cytokine assay (Antigenix America) according to the instructions of the manufacturer on a LSRII flow cytometer (Becton Dickinson).

Amino acid analysis. Amino acids were measured by high-performance liquid chromatography (HPLC) using precolumn derivatization with o-phthaldialdehyde (OPA). OPA is a fluorophore, which - when combined with an amino acid — forms an isoindole that can easily be detected and quantified. Plasma 
samples were deproteinized with an equal volume of $6 \%$ sulfosalicylic acid containing $50 \mu \mathrm{M}$ ethionine as an internal standard. After 5 minutes of centrifugation at $1,000 \mathrm{~g}$, the supernate was placed into an autosampler, where it was mixed with OPA and injected onto the column according to an injector program. The HPLC system was an Agilent 1100 with ChemStation (Agilent Technologies) consisting of a binary pump, degasser, fluoresence dectector, and autosampler. Chromatographic separations were carried out using a Supelcosil LC-18 column $150 \mathrm{~cm} \times 4.6 \mathrm{~mm}, 5 \mu \mathrm{m}$ (Sulpelco), which was protected by an appropriate guard column. All reagents were HPLC grade and prepared with $18 \mathrm{M} \Omega$ water. The mobile phase consisted of $20 \mathrm{mM}$ sodium acetate, $\mathrm{pH} 5.7$, with 4.0\% tetrahydrofuran. Buffer B was methanol. All chemicals are from Sigma-Aldrich. A gradient was used with percent B increasing to $100 \%$ over 44 minutes at $280^{\circ} \mathrm{C}$. Twenty-one amino acid standards at appropriate concentrations were used for calibration and measured by fluorescence detector using excitation $340 \mathrm{~nm}$ and emission $455 \mathrm{~nm}$ (64).

CD4 $T$ cell polarization. Splenocytes were harvested to analyze Th cell differentiation. IL-4-, IL-17A-, IFN- $\gamma$-, and Foxp3-expressing CD4 ${ }^{+} \mathrm{T}$ cells were quantified by flow cytometry using the mouse Th1/Th2/ Th17/Treg phenotyping kit (BD Biosciences).

Statistics. Logistic regression analyses were used to estimate ORs of asthma patients for a comparison of AA with GG. A multivariable logistic regression model provided an adjusted OR estimate, with age, sex, and smoking history as covariates. Males and females were compared with respect to the frequency of asthma and other categorical characteristics using $\chi^{2}$ tests, and they were compared with respect to quantitative characteristics using the Wilcoxon rank sum test. One-way ANOVA was used for comparison across groups.

Data are shown as mean \pm SEM unless described differently. Statistical analysis was performed using JMP 7 software program. Two-tailed Student's $t$ test for parametric and a Wilcoxon test for nonparametric data were used as appropriate. A log transformation was performed on skewed data for statistical analysis. $P$ values smaller than 0.05 were considered significant. Bonferroni method was used to account for multiple comparisons.

Study approval. All animal experiments were approved by the Cleveland Clinic IACUC (Cleveland, Ohio). Local IRB approval and informed consent from all human participants was obtained.

\section{Author contributions}

$\mathrm{KA}$ and $\mathrm{SE}$ designed the research studies. $\mathrm{CB}, \mathrm{CDL}, \mathrm{MA}, \mathrm{MF}, \mathrm{NW}, \mathrm{KW}, \mathrm{SK}$, and WX performed the experiments. CB, CDL, MA, MF, NW, KW, SK, and WX acquired data. CB, KA, CDL, MA, MF, NW, KW, SK, and WX analyzed the data. KA, DAM, WX, and SE wrote the manuscript.

\section{Acknowledgments}

The authors thank Kimberly Queisser for excellent technical assistance, the Lerner Research Institute Imaging Core for assistance with histology and immunohistochemistry and the Flow Cytometry Core for assistance with cytokine bead assay. We also thank Jeff Hammel for assistance with statistical analyses. Supported by NIH grants HL103453, HL081064, HL 60917, and HL109250, and the Alfred Lerner Memorial Chair in Innovative Biomedical Research at the Cleveland Clinic.

Address correspondence to: Kewal Asosingh, Department of Inflammation and Immunity, Lerner Research Institute, Cleveland Clinic, NC22, 9500 Euclid Ave, Ohio 44195, USA. Phone: 216.445.6625; Email: asosink@ccf.org.

1. Mukherjee AB, Zhang Z. Allergic asthma: influence of genetic and environmental factors. J Biol Chem. 2011;286(38):32883-32889.

2. DeBerardinis RJ, Thompson CB. Cellular metabolism and disease: what do metabolic outliers teach us? Cell. 2012;148(6):1132-1144.

3. Geiger R, et al. L-Arginine Modulates T Cell Metabolism and Enhances Survival and Anti-tumor Activity. Cell. 2016;167(3):829-842.e13.

4. Xu W, et al. Increased mitochondrial arginine metabolism supports bioenergetics in asthma. J Clin Invest. 2016;126(7):2465-2481

5. Morris SM. Arginine metabolism: boundaries of our knowledge. J Nutr. 2007;137(6 Suppl 2):1602S-1609S.

6. Zimmermann N, et al. Dissection of experimental asthma with DNA microarray analysis identifies arginase in asthma pathogenesis. J Clin Invest. 2003;111(12):1863-1874.

7. Pope SM, et al. Identification of a cooperative mechanism involving interleukin-13 and eotaxin-2 in experimental allergic lung inflammation. J Biol Chem. 2005;280(14):13952-13961.

8. Vonk JM, Postma DS, Maarsingh H, Bruinenberg M, Koppelman GH, Meurs H. Arginase 1 and arginase 2 variations associate with asthma, asthma severity and beta2 agonist and steroid response. Pharmacogenet Genomics. 2010;20(3):179-186.

9. Li H, et al. Genetic polymorphisms in arginase I and II and childhood asthma and atopy. J Allergy Clin Immunol. 
2006;117(1):119-126.

10. Salam MT, Islam T, Gauderman WJ, Gilliland FD. Roles of arginase variants, atopy, and ozone in childhood asthma. J Allergy Clin Immunol. 2009;123(3):596-602.e1

11. Hakonarson $\mathrm{H}$, et al. A major susceptibility gene for asthma maps to chromosome 14q24. Am J Hum Genet. 2002;71(3):483-491.

12. Xu W, et al. Arginine metabolic endotypes related to asthma severity. PLoS One. 2017;12(8):e0183066.

13. Winnica D, et al. Bioenergetic Differences in the Airway Epithelium of Lean Versus Obese Asthmatics Are Driven by Nitric Oxide and Reflected in Circulating Platelets. Antioxid Redox Signal. 2019;31(10):673-686.

14. Barnes PJ. Nitric oxide and asthma. Res Immunol. 1995;146(9):698-702.

15. Comhair SA, Erzurum SC. Redox control of asthma: molecular mechanisms and therapeutic opportunities. Antioxid Redox Signal. 2010;12(1):93-124.

16. Dweik RA, et al. Nitric oxide synthesis in the lung. Regulation by oxygen through a kinetic mechanism. J Clin Invest. 1998;101(3):660-666.

17. Gaston B, Singel D, Doctor A, Stamler JS. S-nitrosothiol signaling in respiratory biology. Am J Respir Crit Care Med. 2006;173(11):1186-1193.

18. Ghosh S, et al. Nitrotyrosine proteome survey in asthma identifies oxidative mechanism of catalase inactivation. $J$ Immunol. 2006;176(9):5587-5597.

19. Gladwin MT, Kim-Shapiro DB. Storage lesion in banked blood due to hemolysis-dependent disruption of nitric oxide homeostasis. Curr Opin Hematol. 2009;16(6):515-523.

20. Green LC, et al. Nitrate biosynthesis in man. Proc Natl Acad Sci USA. 1981;78(12):7764-7768.

21. Guo FH, et al. Molecular mechanisms of increased nitric oxide (NO) in asthma: evidence for transcriptional and post-translational regulation of NO synthesis. J Immunol. 2000;164(11):5970-5980.

22. Guo FH, Erzurum SC. Characterization of inducible nitric oxide synthase expression in human airway epithelium. Environ Health Perspect. 1998;106 Suppl 5:1119-1124.

23. Kobzik L. Translating NO biology into clinical advances: still searching for the right dictionary? Am J Respir Cell Mol Biol. 2009;41(1):9-13.

24. Larsen FJ, et al. Dietary inorganic nitrate improves mitochondrial efficiency in humans. Cell Metab. 2011;13(2):149-159.

25. Leaf CD, Wishnok JS, Tannenbaum SR. L-arginine is a precursor for nitrate biosynthesis in humans. Biochem Biophys Res Commun. 1989;163(2):1032-1037.

26. Singh D, et al. Selective inducible nitric oxide synthase inhibition has no effect on allergen challenge in asthma. Am J Respir Crit Care Med. 2007;176(10):988-993.

27. Moore WC, et al. Characterization of the severe asthma phenotype by the National Heart, Lung, and Blood Institute's Severe Asthma Research Program. J Allergy Clin Immunol. 2007;119(2):405-413.

28. Jarjour NN, et al. Severe asthma: lessons learned from the National Heart, Lung, and Blood Institute Severe Asthma Research Program. Am J Respir Crit Care Med. 2012;185(4):356-362.

29. Jianjun Yang null, et al. T cell-derived inducible nitric oxide synthase switches off Th17 cell differentiation. J Exp Med. 2013;210(7):1447-1462.

30. Vrugt B, Wilson S, Bron A, Holgate ST, Djukanovic R, Aalbers R. Bronchial angiogenesis in severe glucocorticoid-dependent asthma. Eur Respir J. 2000;15(6):1014-1021.

31. Li X, Wilson JW. Increased vascularity of the bronchial mucosa in mild asthma. Am J Respir Crit Care Med. 1997;156(1):229-233.

32. Salvato G. Quantitative and morphological analysis of the vascular bed in bronchial biopsy specimens from asthmatic and non-asthmatic subjects. Thorax. 2001;56(12):902-906.

33. Pascual RM, Peters SP. Airway remodeling contributes to the progressive loss of lung function in asthma: an overview. $J$ Allergy Clin Immunol. 2005;116(3):477-486.

34. Imaoka H, et al. Lung homing of endothelial progenitor cells in humans with asthma after allergen challenge. Am J Respir Crit Care Med. 2011;184(7):771-778.

35. Ochkur SI, et al. Coexpression of IL-5 and eotaxin-2 in mice creates an eosinophil-dependent model of respiratory inflammation with characteristics of severe asthma. J Immunol. 2007;178(12):7879-7889.

36. Asosingh K, et al. Eotaxin-Rich Proangiogenic Hematopoietic Progenitor Cells and CCR3+ Endothelium in the Atopic Asthmatic Response. J Immunol. 2016;196(5):2377-2387.

37. Wang YH, Wills-Karp M. The potential role of interleukin-17 in severe asthma. Curr Allergy Asthma Rep. 2011;11(5):388-394.

38. Honorati MC, Neri S, Cattini L, Facchini A. Interleukin-17, a regulator of angiogenic factor release by synovial fibroblasts. Osteoarthr Cartil. 2006;14(4):345-352.

39. Duan QL, et al. Regulatory haplotypes in ARG1 are associated with altered bronchodilator response. Am J Respir Crit Care Med. 2011;183(4):449-454.

40. Morris CR, Poljakovic M, Lavrisha L, Machado L, Kuypers FA, Morris SM. Decreased arginine bioavailability and increased serum arginase activity in asthma. Am J Respir Crit Care Med. 2004;170(2):148-153.

41. De Sanctis GT, et al. Contribution of nitric oxide synthases 1, 2, and 3 to airway hyperresponsiveness and inflammation in a murine model of asthma. J Exp Med. 1999;189(10):1621-1630.

42. Dweik RA, et al. NO chemical events in the human airway during the immediate and late antigen-induced asthmatic response. Proc Natl Acad Sci USA. 2001;98(5):2622-2627.

43. Naura AS, et al. Requirement for inducible nitric oxide synthase in chronic allergen exposure-induced pulmonary fibrosis but not inflammation. J Immunol. 2010;185(5):3076-3085.

44. Byrne AJ, Jones CP, Gowers K, Rankin SM, Lloyd CM. Lung macrophages contribute to house dust mite driven airway remodeling via HIF-1 $\alpha$. PLoS One. 2013;8(7):e69246.

45. Fahy JV. Eosinophilic and neutrophilic inflammation in asthma: insights from clinical studies. Proc Am Thorac Soc 2009;6(3):256-259.

46. Lambrecht BN, Hammad H. The immunology of asthma. Nat Immunol. 2015;16(1):45-56.

47. Du JW, Xu KY, Fang LY, Qi XL. Interleukin-17, produced by lymphocytes, promotes tumor growth and angiogenesis in a 
mouse model of breast cancer. Mol Med Rep. 2012;6(5):1099-1102.

48. Numasaki M, et al. Interleukin-17 promotes angiogenesis and tumor growth. Blood. 2003;101(7):2620-2627.

49. Pickens SR, Volin MV, Mandelin AM, Kolls JK, Pope RM, Shahrara S. IL-17 contributes to angiogenesis in rheumatoid arthritis. J Immunol. 2010;184(6):3233-3241.

50. Murugaiyan G, Saha B. Protumor vs antitumor functions of IL-17. J Immunol. 2009;183(7):4169-4175.

51. Takeda A, et al. CCR3 is a target for age-related macular degeneration diagnosis and therapy. Nature. 2009;460(7252):225-230.

52. Asosingh K, Hanson JD, Cheng G, Aronica MA, Erzurum SC. Allergen-induced, eotaxin-rich, proangiogenic bone marrow progenitors: a blood-borne cellular envoy for lung eosinophilia. J Allergy Clin Immunol. 2010;125(4):918-925.

53. Amerio P, et al. Eotaxins and CCR3 receptor in inflammatory and allergic skin diseases: therapeutical implications. Curr Drug Targets Inflamm Allergy. 2003;2(1):81-94.

54. Chesné J, Braza F, Mahay G, Brouard S, Aronica M, Magnan A. IL-17 in severe asthma. Where do we stand? Am J Respir Crit Care Med. 2014;190(10):1094-1101.

55. Kim HY, et al. Interleukin-17-producing innate lymphoid cells and the NLRP3 inflammasome facilitate obesity-associated airway hyperreactivity. Nat Med. 2014;20(1):54-61.

56. Song C, et al. IL-17-producing alveolar macrophages mediate allergic lung inflammation related to asthma. J Immunol. 2008;181(9):6117-6124.

57. Hawkins GA, et al. The IL6R variation Asp(358)Ala is a potential modifier of lung function in subjects with asthma. J Allergy Clin Immunol. 2012;130(2):510-5.e1.

58. Li X, et al. Genome-wide association studies of asthma indicate opposite immunopathogenesis direction from autoimmune diseases. J Allergy Clin Immunol. 2012;130(4):861-8.e7.

59. Laubach VE, Shesely EG, Smithies O, Sherman PA. Mice lacking inducible nitric oxide synthase are not resistant to lipopolysaccharide-induced death. Proc Natl Acad Sci USA. 1995;92(23):10688-10692.

60. Shi O, Morris SM, Zoghbi H, Porter CW, O'Brien WE. Generation of a mouse model for arginase II deficiency by targeted disruption of the arginase II gene. Mol Cell Biol. 2001;21(3):811-813.

61. Klein Wolterink RG, et al. Pulmonary innate lymphoid cells are major producers of IL-5 and IL-13 in murine models of allergic asthma. Eur J Immunol. 2012;42(5):1106-1116.

62. Willart MA, et al. Interleukin-1 $\alpha$ controls allergic sensitization to inhaled house dust mite via the epithelial release of GM-CSF and IL-33. J Exp Med. 2012;209(8):1505-1517.

63. Asosingh K, et al. Nascent endothelium initiates Th2 polarization of asthma. J Immunol. 2013;190(7):3458-3465

64. Wu G, Morris SM. Arginine metabolism: nitric oxide and beyond. Biochem J. 1998;336(Pt 1):1-17. 